\title{
Undertriage of major trauma patients at a university hospital: a retrospective cohort study
}

Terje Nordgarden $^{1^{*}}$ (D), Peter Odland ${ }^{1}$, Anne Berit Guttormsen ${ }^{2,3}$ and Kristina Stølen Ugelvik ${ }^{4}$

\begin{abstract}
Background: Studies show increased mortality among severely injured patients not met by trauma team. Proper triage is important to ensure that all severely injured patients receive vital trauma care. In 2017 a new national trauma plan was implemented in Norway, which recommended the use of a modified version of "Guidelines for Field Triage of Injured Patients" to identify severely injured patients.

Methods: A retrospective study of 30,444 patients admitted to Haukeland University Hospital in 2013, with ICD-10 injury codes upon discharge. The exclusion criteria were department affiliation considered irrelevant when identifying trauma, patients with injuries that resulted in Injury Severity Score $<15$, patients that did receive trauma team, and patients admitted $>24 \mathrm{~h}$ after time of injury. Information from patient records of every severely injured patient admitted in 2013 was obtained in order to investigate the sensitivity of the new guidelines.
\end{abstract}

Results: Trauma team activation was performed in 369 admissions and 85 patients were identified as major trauma. Ten severely injured patients did not receive trauma team resuscitation, resulting in an undertriage of $10.5 \%$. Nine out of ten patients were men, median age 54 years. Five patients were 60 years or older. All of the undertriaged patients experienced fall from low height $(<4 \mathrm{~m})$. Traumatic brain injury was seen in six patients. Six patients had a Glasgow Coma Scale score $\leq 13$. The new trauma activation guidelines had a sensitivity of $95.0 \%$ in our 2013 trauma population. The degree of undertriage could have been reduced to $4.0 \%$ had the guidelines been implemented and correctly applied.

Conclusions: The rate of undertriage at Haukeland University Hospital in 2013 was above the recommendations of less than $5 \%$. Use of the new trauma guidelines showed increased triage precision in the present trauma population.

Keywords: American College of Surgeons, Committee on trauma, Guidelines for Field Triage of Injured Patients, Haukeland University Hospital, National Trauma Plan, Norway, Trauma, Trauma team, Undertriage

\section{Background}

Studies show increased survival among severely injured patients met by a dedicated trauma team [1-6] and that implementation of trauma centers improve outcome in trauma patients $[1,7-13]$. Trauma centers require a vast amount of human and financial resources to function as intended $[14,15]$. In order to justify the expense, it is essential to maintain a reliable system able to identify

\footnotetext{
*Correspondence: terje.n@outlook.com

${ }^{1}$ Faculty of Medicine, University of Bergen, Haukelandsveien 28, 5009 Bergen, Norway

Full list of author information is available at the end of the article
}

patients with severe injury, while excluding non- and minor injuries.

Early trauma evaluation can be a challenge. In light of its dynamic nature, the wide range of possible injuries and the limited tools at disposal, occasional mistriage is to be expected. Mistriage is divided into under- and overtriage: Undertriage is defined as the proportion of severely injured patients not managed by a dedicated trauma team, while overtriage is the proportion of patients not severely injured but still receiving such care. The degree of undertriage is an indicator of the sensitivity of the trauma system. Overtriage is unfortunate as it is costly and exhausts

(C) The Author(s). 2018 Open Access This article is distributed under the terms of the Creative Commons Attribution 4.0 International License (http://creativecommons.org/licenses/by/4.0/), which permits unrestricted use, distribution, and 
human and financial recourses $[16,17]$. Undertriage of less than $5 \%$ and overtriage of $25-30 \%$ is deemed acceptable according to the American College of Surgeons, Committee on Trauma [18].

All the Regional Health Thrusts in Norway have recently implemented the "National Trauma Plan 2016", a national protocol for managing trauma patients. The new trauma plan recommends the use of a modified version of the "Guidelines for Field Triage of Injured Patients" nationwide for field triage as well as in hospitals, including pediatric trauma (Figs. 1 and 2) [19]. The guidelines recommend a four-stage triage process based on deviations in vital signs, anatomical injury, mechanism of injury (MOI) and special considerations, in descending priority. Patients who fail to meet the physiological criteria should be evaluated in terms of anatomical injury, then in terms of mechanism of injury, and so on. The decision scheme is widely implemented in the US health care system [20, 21], has been regularly revised since its inception in 1976, and underwent its latest update in

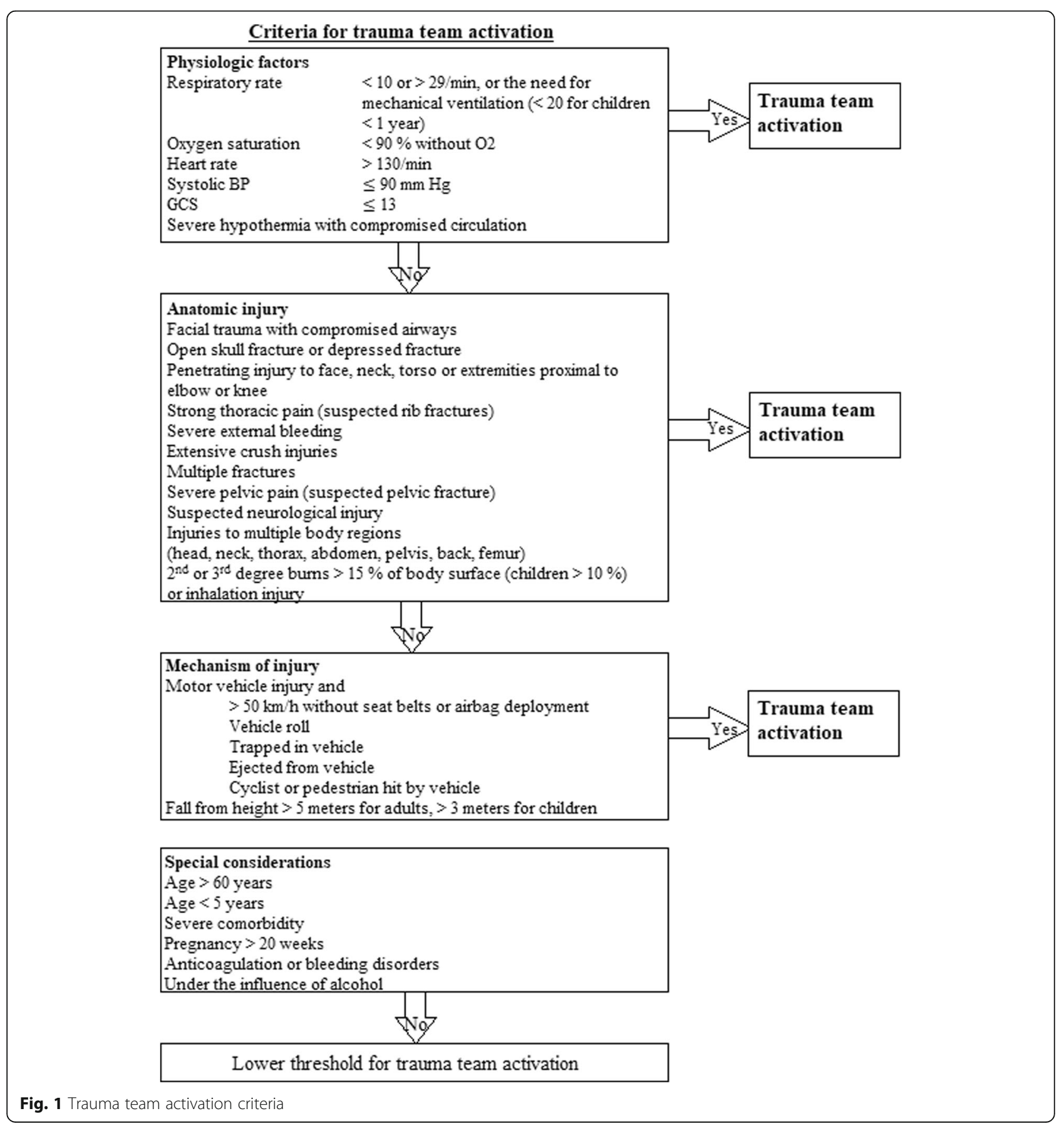




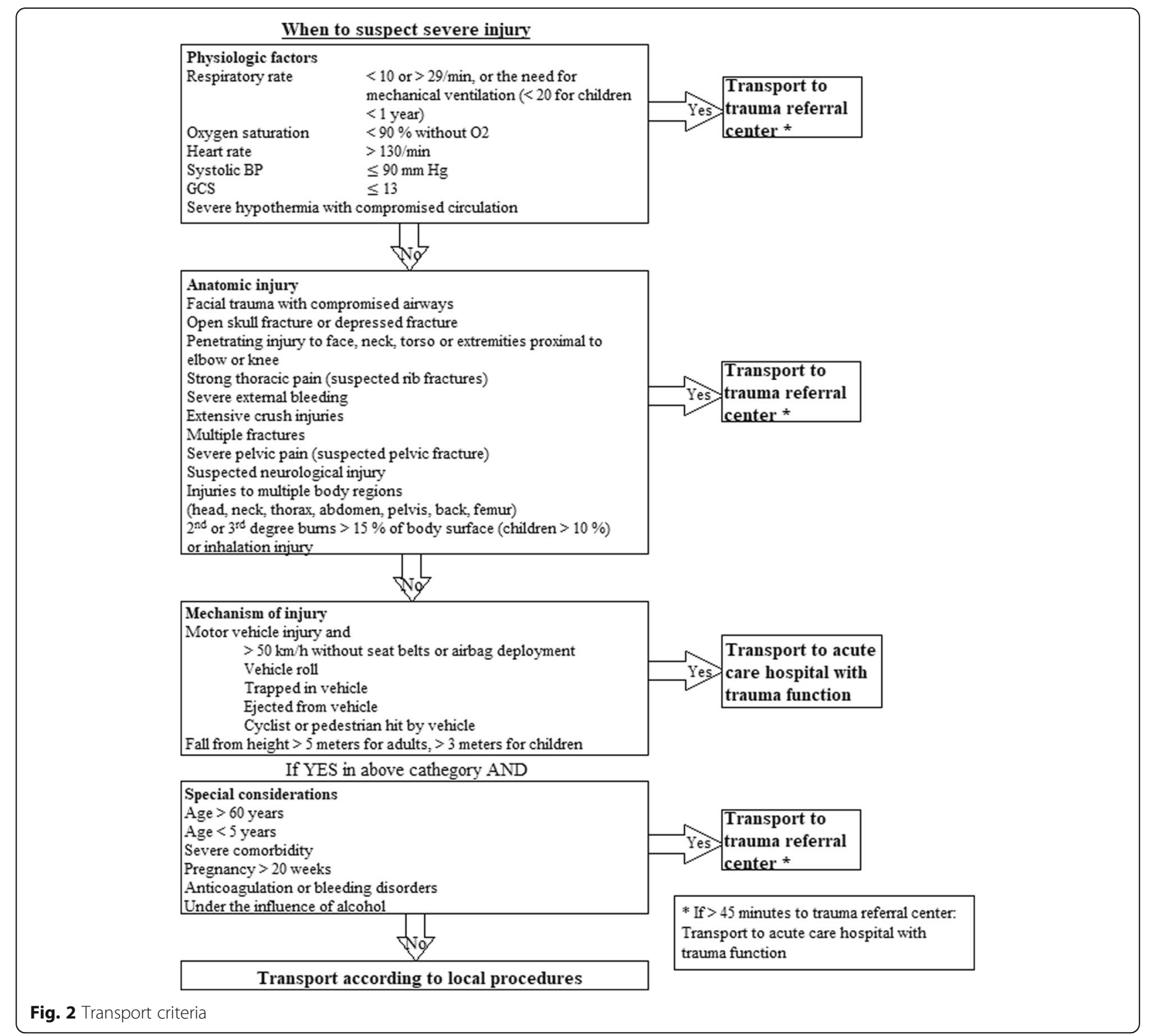

2011 [20]. Several studies have found the tool to be highly sensitive for identifying severe trauma (>95\%) $[22,23]$. However, some studies indicate a lower sensitivity than previously thought [24], especially among elderly patients [25-28].

The Norwegian health system is divided into four health thrusts. Each thrust has a regional trauma center in addition to acute care hospitals with trauma function. Trauma centers provide definite care for all injuries and have access to all surgical specialties. Our study was conducted at Haukeland University Hospital (HUH). HUH is the local hospital for a population of 380,000 inhabitants and also serves as a regional trauma center for 1.1 million people in Hordaland, Rogaland and Sogn og Fjordane counties [29]. This region consists of five acute care hospitals, with $\mathrm{HUH}$ functioning as the regional trauma center in Western Norway. The national burn unit in Norway is located at HUH. HUH admits approximately 350-400 trauma patients each year, of which 7590 have ISS $\geq 15$.

Trauma team activation at HUH is based on initial pre-hospital information or on in-hospital clinical assessment. Single-tiered trauma team is used regardless of the assumed degree of injury. Until 2016, HUH used local criteria for trauma team activation. These criteria were mainly centered on anatomical injury, MOI and, to a lesser extent, vital signs. Despite undertriage being acknowledged as a useful tool when assessing the quality of a trauma system, no systematic investigations of triage accuracy have previously been conducted at HUH. The purpose of this study was twofold: to investigate the rate of undertriage at $\mathrm{HUH}$, and to evaluate the ability of the 
modified version of the "Guidelines for Field Triage of Injured Patients" to identify severely injured patients.

\section{Methods}

Our retrospective study included 30,444 patients admitted to HUH in 2013. Data were obtained from HUH's patient registry, which entails information about all patients who have received specialized health care services. Patient identity was anonymized. The data set was based on discharge codes according to the 10th version of the International Statistical Classification of Diseases and Related Health Problems (ICD-10). The patients in the data set had codes ranging from S00 to T88.

Injury Severity Score (ISS) is a well-established scoring system for multi trauma, used to determine injury severity and risk of mortality [30]. Each injury is categorized according to the Abbreviated Injury Scale (AIS) [31]. ISS is the sum of squares from the highest AIS grades in the three most severely injured ISS body regions (see Appendix for further details).

In order to find potentially undertriaged patients among the 30,444 admissions, we excluded patients admitted to departments considered unlikely to handle trauma (Table 1) and patients with single injuries where the AIS score was $\leq 3$ (Table 2). Patients with multiple injuries in the same body region where the highest injury gave AIS $\leq 3$ and where there were no injuries to other body regions, were also excluded (Table 3 ). Lastly, we excluded patients registered as trauma team recipients. This process was done by using filtration in Microsoft Excel and the local trauma register (see Appendix for details). Following this, 2579 medical records were manually reviewed by the first and second author. We now excluded patients with ISS $<15$ or admitted $>24 \mathrm{~h}$ after time of injury. Every patient with ISS $\geq 13$ was double-checked by the last author. One patient with ISS $\geq 15$ was already registered as undertriaged in the local trauma register but was not identified in our filtration due to incorrect ICD-10 coding upon discharge (lack of $\mathrm{S}$ or $\mathrm{T}$ codes). Burn patients were excluded. The reason for this is that patients with isolated burn injuries were not routinely considered in need of trauma team according to practice in 2013. They were instead handled by a dedicated team from the burn unit. The remaining patients had ISS $\geq 15$, were admitted $<24 \mathrm{~h}$ after time of injury and not met by trauma team (Fig. 3).

Sensitivity and undertriage was defined in the same way as in another Norwegian study: Sensitivity as the proportion of severely injured patients managed by trauma team, and undertriage as the probability of a severely injured patient not receiving trauma team resuscitation during admission (i.e. 1-Sensitivity) [32]. The guidelines' sensitivity was assessed by acquiring vital
Table 1 Included and excluded departments

\begin{tabular}{|c|c|}
\hline Included departments & Excluded departments \\
\hline Dep. of Orthopedic Surgery & $\begin{array}{l}\text { Dep. for sexually transmitted } \\
\text { diseases }\end{array}$ \\
\hline Dep. of Internal Medicine & Dep. of Rehabilitation \\
\hline $\begin{array}{l}\text { Dep. of Plastic and Reconstructive } \\
\text { Surgery }\end{array}$ & $\begin{array}{l}\text { Dep. of Breast and Endocrine } \\
\text { Surgery }\end{array}$ \\
\hline Dep. of Neurology & $\begin{array}{l}\text { Dep. of immunology and } \\
\text { transfusion medicine }\end{array}$ \\
\hline Dep. of Thoracic Surgery & $\begin{array}{l}\text { Dep. of Oncology and Medical } \\
\text { Physics }\end{array}$ \\
\hline Dep. of Gastric Surgery & Dep. of Foreign treatment \\
\hline Dep. of Otorhinolaryngology & Dep. of Physiotherapy \\
\hline The Burn Unit & $\begin{array}{l}\text { Dep. of Habilitation services for } \\
\text { adults }\end{array}$ \\
\hline Dep. of Ophthalmology & Dep. of Dermatology \\
\hline $\begin{array}{l}\text { Dep. of Pulmonology and Respiratory } \\
\text { Medicine }\end{array}$ & Kysthospitalet i Hagevik \\
\hline Dep. of Vascular Surgery & Dep. of Orthopedic Rehabilitation \\
\hline Dep. of Pediatrics & Dep. of Rheumatology \\
\hline $\begin{array}{l}\text { The Department of Anesthesiology, } \\
\text { Perioperative and Pain Medicine }\end{array}$ & Dep. of Palliative Care \\
\hline Dep. of Neurological Surgery & Dep. of Occupational Medicine \\
\hline Dep. of Obstetrics and Gynecology & Voss Delivery Ward \\
\hline Dep. of Thoracic Surgery & Voss Gynecology Ward \\
\hline Dep. of Oral and Maxillofacial Surgery & Voss Medical Ward \\
\hline Dep. of Urologic Surgery & Voss Dep. of Physiotherapy \\
\hline
\end{tabular}

signs, anatomical injury and MOI from emergency department journals and emergency medical technician journals from every severely injured patient. We did not investigate the decision scheme's specificity as this was considered beyond the scope of our study.

Informed consent was not required, as undertriage is part of the trauma system quality assessment. Approvals from the Regional Committee for Research Ethics and the Data Protection Official were waived (ref. no. 2015/259).

\section{Results}

In 2013, 85 of the 369 patients who were met by trauma team were severely injured (ISS $\geq 15$ ). Ten severely injured patients did not receive trauma team resuscitation. In total, 95 patients qualifying for trauma team activation were admitted $(85+10)$. This gives an undertriage of $10.5 \%$ (1-85/95 or $10 / 95)$ (see Table 4 ).

A further look into the characteristics among the undertriaged patients disclosed the following: Nearly all (nine) were men, with a median age of 54 years and median ISS of 16 . Half of the patients were 60 years or older. With regard to the mechanism of injury, all of the 
Table 2 Excluded single injury ICD-10 codes

\begin{tabular}{|c|c|c|c|c|c|c|c|c|}
\hline \multicolumn{9}{|l|}{ S-Codes } \\
\hline \multirow[t]{2}{*}{ Injuries to the head } & soo & S022 & S023 & S025 & S026 & S028 & S03 & S04 \\
\hline & S05 & S06 & S08 & S09 & & & & \\
\hline Injuries to the neck & S10 & S16 & & & & & & \\
\hline Injuries to the thorax & S20 & S223 & & & & & & \\
\hline $\begin{array}{l}\text { Injuries to the abdomen, lower back, lumbar spine, pelvis and } \\
\text { external genitals }\end{array}$ & S30 & & & & & & & \\
\hline Injuries to shoulder and upper arm & $\$ 40$ & S41 & S42 & $\$ 43$ & S44 & S45 & S46 & \\
\hline Injuries to elbow and forearm & S50 & S51 & S54 & S56 & S57 & S59 & & \\
\hline Injuries to the wrist, hand and fingers & $S 60$ & S61 & S62 & S63 & S64 & S66 & & \\
\hline Injuries to hip and thigh & S70 & S72 & S73 & S74 & S76 & & & \\
\hline Injuries to knee and lower leg & S80 & S81 & S82 & S83 & S84 & S85 & S86 & \\
\hline Injuries to ankle and foot & $\$ 90$ & S91 & 592 & 593 & S94 & S95 & S96 & 598 \\
\hline \multicolumn{9}{|l|}{ T-Codes } \\
\hline Injuries involving multiple body regions & T00 & & & & & & & \\
\hline Effects of foreign body entering through natural orifice & T15 & T16 & $\mathrm{T} 17$ & T18 & T19 & & & \\
\hline Burns and corrosions of external body surface, specified by site & T23 & T25 & & & & & & \\
\hline Burns and corrosions confined to eye and internal organs & T26 & & & & & & & \\
\hline Burns and corrosions of multiple and unspecified body regions & T301 & & & & & & & \\
\hline $\begin{array}{l}\text { Poisoning by, adverse effect of and under dosing of drugs, } \\
\text { medicaments and biological substances }\end{array}$ & T4n & T41 & T50 & & & & & \\
\hline \multirow[t]{2}{*}{ Toxic effects of substances chiefly nonmedicinal as to source } & T51 & T52 & T53 & T54 & T55 & T56 & T57 & T58 \\
\hline & T59 & T60 & T61 & T62 & T63 & T64 & T65 & \\
\hline \multirow[t]{2}{*}{ Other and unspecified effects of external causes } & T66 & T67 & T68 & T69 & T70 & T71 & $\mathrm{T} 72$ & $\mathrm{~T} 73$ \\
\hline & T74 & T75 & T76 & $\mathrm{T} 77$ & T78 & & & \\
\hline \multirow[t]{2}{*}{ Complications of surgical and medical care, not elsewhere classified } & T80 & T81 & T82 & T83 & T84 & T85 & T86 & T87 \\
\hline & T88 & & & & & & & \\
\hline \multirow{2}{*}{$\begin{array}{l}\text { Complications after injury, poisoning and other consequences of } \\
\text { external injury }\end{array}$} & T90 & T91 & T92 & T93 & T94 & T95 & T96 & T97 \\
\hline & T98 & & & & & & & \\
\hline
\end{tabular}

Any patient with these S- and T-codes as its only injury code, were excluded. Single injuries with AIS $\leq 3$ and would not result in ISS $>9$. ICD-10 T40-78 and T-8099 were excluded since they are not a direct consequence of trauma

Table 3 Excluded multiple injury ICD-10 codes

\begin{tabular}{|c|c|c|c|c|c|c|c|c|}
\hline \multirow[t]{2}{*}{ Injuries to the head } & SO0 & S022 & S023 & S025 & S026 & S03 & S04 & S05 \\
\hline & S08 & S09 & & & & & & \\
\hline Injuries to shoulder and upper arm & S40 & S42 & $\$ 43$ & S44 & S45 & S46 & & \\
\hline \multirow[t]{2}{*}{ Injuries to elbow and forearm and injuries to the wrist, hand and fingers } & $\mathrm{S} 50$ & S51 & S52 & S53 & S54 & S55 & S56 & S57 \\
\hline & $\mathrm{S} 60$ & S61 & S62 & S63 & S64 & S66 & S67 & S69 \\
\hline \multirow[t]{2}{*}{ Injuries to knee and lower leg and injuries to ankle and foot } & $\mathrm{S} 80$ & S81 & 582 & 583 & 584 & S86 & & \\
\hline & $\mathrm{S} 90$ & S91 & S92 & S93 & S94 & S95 & S96 & 598 \\
\hline
\end{tabular}




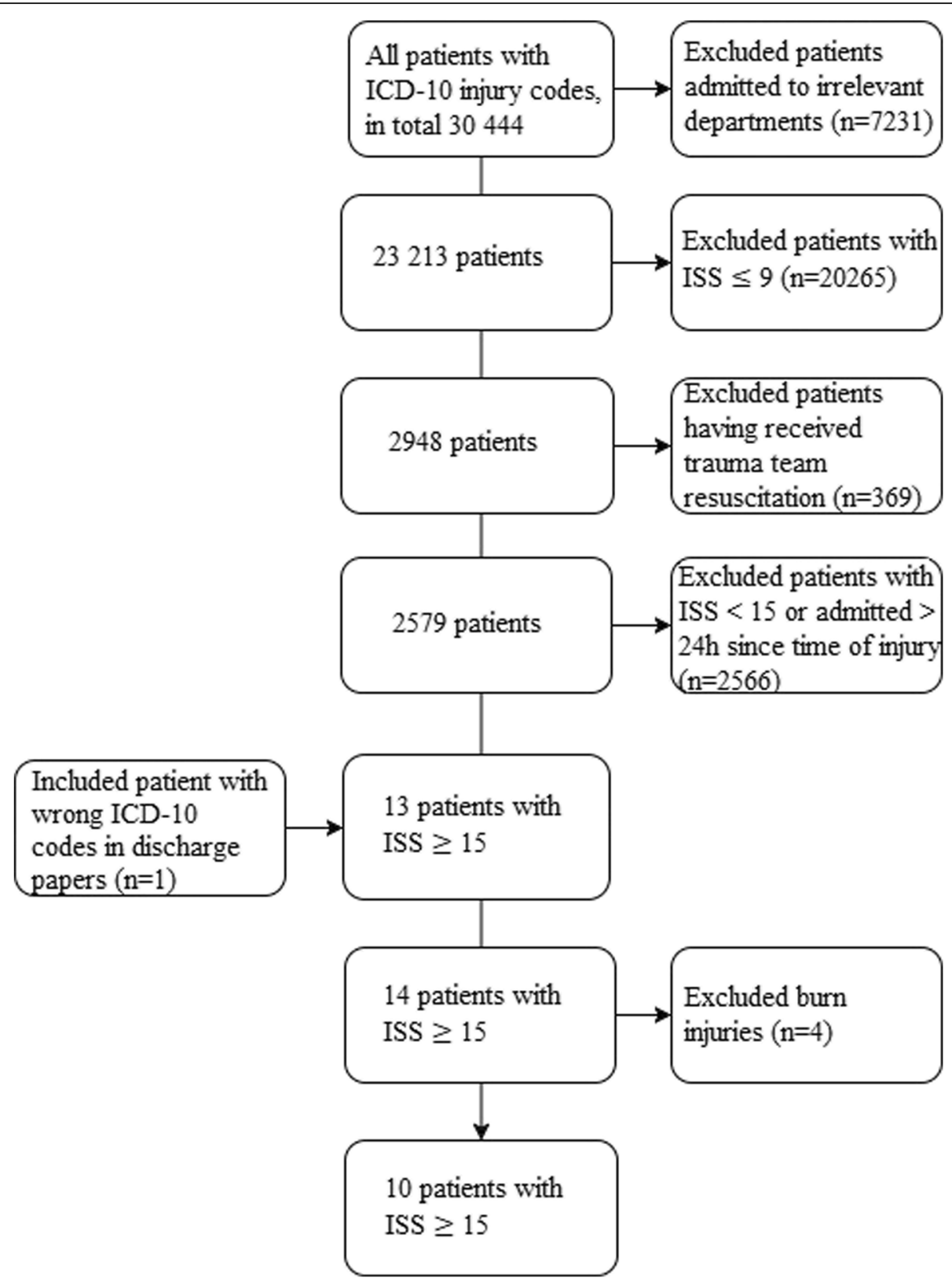

Fig. 3 Methods

Table 4 Undertriage calculation

\begin{tabular}{llll}
\hline & $\begin{array}{l}\text { Severely } \\
\text { injured }\end{array}$ & $\begin{array}{l}\text { Not severely } \\
\text { injured }\end{array}$ & Total \\
\hline Trauma team activation & 85 & 284 & 369 \\
No trauma team activation & 10 & 30,065 & 30,075 \\
Total & 95 & 30,349 & 30,444 \\
\hline
\end{tabular}

Sensitivity: 85/95

Undertriage: 1 - Sensitivity $=1-85 / 95$ or $10 / 95=10.5 \%$ patients experienced blunt trauma by fall from low heights $(<4 \mathrm{~m})$. Eight patients had injuries located to a single anatomical region, while two patients had $\geq 2$ body regions affected. A majority (seven) experienced injuries to head or neck.

Six patients were diagnosed with traumatic brain injury (TBI) (See Appendix for definition). Six patients had Glasgow Coma Scale score (GCS) $\leq 13$, either in- or out of hospital. The patients' Glasgow Outcome Score (GOS) (see Appendix) ranged between 1 and 5. Seven patients scored 5, one scored 4. The remaining two patients died (GOS 1). The deceased were aged 79 and 86, with ISS 26 
and 25 respectively, and both died from injuries to a single body region. See Table 5 for further details.

We retrospectively applied the Norwegian "Guidelines for Field Triage of Injured Patients" as stated in the national trauma plan, on all the severely injured trauma patients in 2013 (patients with ISS $\geq 15$, both undertriaged and correctly triaged) to evaluate the guidelines' ability to identify severe trauma. Out of the 95 severely injured patients, the decision scheme identified 90 patients, showing a sensitivity of $95.0 \%$. Deviation in vital signs was the highest-ranking criterion in 65 patients (68.0\%). Among the undertriaged patients, six out of ten could have been identified as severe trauma based on vital sign deviation (reduced GCS). Anatomical injuries were the highest-ranking criterion in 21 patients $(22.0 \%)$. Four $(4.0 \%)$ were identified from MOI alone. None of the undertriaged patients could have been identified based on anatomic injury or MOI alone. By retrospectively applying the guidelines to the 2013 patients, the undertriage was reduced from 10.5 to $4.0 \%$.

\section{Discussion}

Retrospective data from 2013 indicate 10.5\% undertriage among trauma patients at $\mathrm{HUH}$. Our data imply a rate of undertriage at $\mathrm{HUH}$ which is more than twice as high as national recommended benchmarks [19]. Scandinavian studies have reported similar or higher rates at other Trauma Centers [32-35]. Studies from American Emergency Departments have found even higher undertriage, ranging from 40 to $70 \%$ [27, 36], demonstrating that assessing injury severity remains a significant challenge.

The high rate of undertriage among elderly trauma patients is also described elsewhere [24-28, 37, 38], including in studies using "Field Triage of Injured Patients" [25, 28]. Our data shows a skewness towards high age, but the small sample size prevents us from making any firm conclusions. Moreover, some have pointed out that vital signs are less reliable to predict injury severity among patients $>65$ years of age [37, 39]. Other studies have found increased mortality risk among elderly patients after ground level falls [40, 41]. Such MOI is not severe enough to activate trauma team, and the high-risk patients should therefore be identified by different means. Additionally, elderly injured patients raise unique challenges, such as potential for higher degree of comorbidity, use of anticoagulants, higher operative risk, and secondary medical complications. As a consequence, the trauma related mortality is higher in the geriatric population [42, 43]. To counter this, high age alone has been suggested as a criterion for trauma team activation [44, 45]. This is not current triage practice in Norway [19]. Still, age $>60$ years is a criterion under "Special considerations" which should lower the threshold for trauma team activation and referral to regional trauma center if transport time $<45 \mathrm{~min}$. Awareness of the special circumstances related to this patient group might aid the triage process and possibly reduce trauma mortality.

Several studies have found that undertriage regularly affects patients with head injury [24, 27, 33]. Xiang et al. reported that $>40 \%$ of the undertriaged trauma patient diagnosis were TBIs (See Appendix for definition). Our data showed the same trend, as more than half of the patients (6/10) were diagnosed with TBI. TBI leads to increased mortality and permanent disabilities [46-50], making early access to proper care crucial.

Vital signs have been proven useful when identifying severe trauma $[32,51-53]$ and GCS has shown to be a good predictor of mortality [54-56]. Pearson and colleagues found that patients with TBI (See Appendix for definition) and a GCS score $\leq 13$ were 17 times more likely to die compared to those with a higher GCS score, after controlling for age, gender, race, ISS and length of hospital stay [57]. Others have criticized GCS for its poor ability to predict isolated head injuries among older trauma patients [58].

Our findings suggest that the "Guidelines for Field Triage of Injured Patients" have a higher sensitivity (95\%) than indicated by recent studies [25, 28]. The lowest sensitivity (66\%) was reported in a prospective study from 2016 including 53,487 patients [28]. A contributing factor behind this discrepancy could be that our study population was sampled from a single regional trauma center only, excluding acute care hospitals in our health region. We are unable to determine to what extent severely injured patients were incorrectly transported to acute care hospitals with trauma function, without access to the relevant care. This means that our study cannot appraise the guidelines' ability to identify patients suitable for direct transport or transfer to a regional trauma center, only their ability to identify in-hospital severe trauma and need for trauma team activation. Consequently, we can neither confirm nor disconfirm the findings of recent studies suggesting that transport to lower tiered hospitals (both trauma and non-trauma hospitals) contributes to the guidelines' low sensitivity [25, 28].

Although the "Guidelines for Field Triage of Injured Patients" had a high total sensitivity (95.0\%), only $68.0 \%$ of the severely injured patients were identified based on vital signs alterations, proving that vital signs alone were insufficient to identify severe trauma. However, the sensitivity improved substantially by combining vital sign deviations with defined anatomical injuries. Cook and colleges hypothesized that the use of vital signs and anatomical injury alone might be sufficient to identify need of trauma team [59]. MOI alone was able to identify 


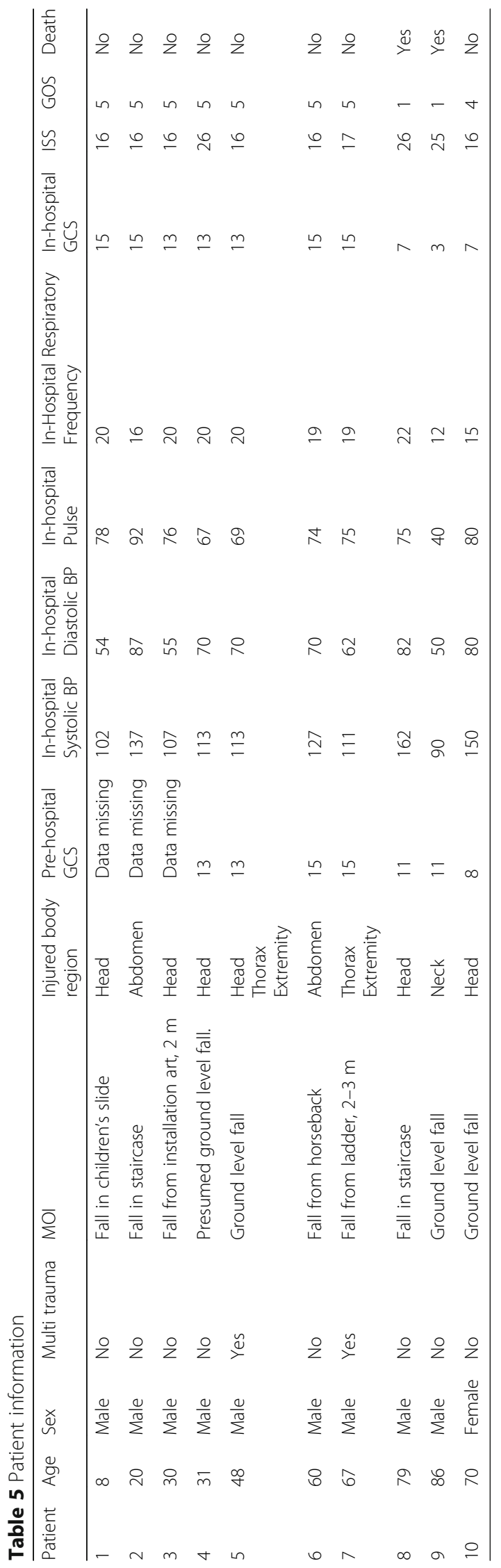


only a small portion of severely injured patients. However, MOI inclusion was required to achieve the desired 95\% sensitivity, which is in line with what prior studies have indicated. Based on our limited data, we recommend adherence to the new guidelines and propose implementing simple tools such as checklists to use both out-of- and in-hospital.

There are several limitations in our study. The most important one is the low sample size, due to both short study length, low trauma volume and the amount of severe trauma admitted to HUH per year. The findings should therefore be interpreted cautiously, bearing in mind the possible implications low sample size may have for their representativeness. Additionally, only patients admitted to a single trauma referral center was included. It is therefore possible that regional characteristics have influenced our trauma population. Only ISS score was used to evaluate trauma severity. This is recommended by both the national trauma plan and American College of Surgeons in quality assessment [18, 19], while being challenged by others for its low ability to predict outcome compared to other trauma scoring systems [60-64]. Patient injuries were recorded using ICD-10 codes. Given the possibility of erroneous coding in the discharge papers, some undertriaged patients may have been missed. Lastly, each injury was assigned the closest corresponding AIS-code, a procedure that could reduce the accuracy of the individual injury descriptions.

\section{Conclusion}

Undertriage at $\mathrm{HUH}$ was $10.5 \%$. Among the undertriaged, elderly patients with low level falls and subsequently isolated head and neck injuries dominated. With correct use of the modified version of "Guidelines for Field Triage of Injured Patients" the rate of undertriage could have been reduced by more than $50 \%$, thereby keeping in line with the recommended $<5 \%$ undertriage. Our data indicate that the guidelines have a high sensitivity when identifying severely injured patients in need of trauma team activation.

\section{Appendix}

\section{AIS and ISS calculation}

Abbreviated Injury Scale is an anatomical-based coding system. As explained in the AIS 2005 manual (update 2008) each injury is assigned a unique seven-digit code describing type, location and severity.

AIS grades the severity of each injury in the following manner:

$$
\begin{aligned}
& 0 \text { - No injury. } \\
& 1 \text { - Minor. } \\
& 2 \text { - Moderate. } \\
& 3 \text {-Severe (not life-threatening). }
\end{aligned}
$$

4 -Severe (life threatening, survival probable).

5 -Severe (critical, survival uncertain).

6 -Maximal, possibly fatal.

In order to calculate the Injury Severity Score (ISS) the body is divided into six body regions. The manual describes ISS as the sum of squares from the highest AIS grades in the three most severely injured ISS body regions.

$$
I S S=A^{2}+B^{2}+C^{2}
$$

$\mathrm{A}, \mathrm{B}$ and $\mathrm{C}$ are the AIS scores from the three most severely injured ISS body regions. The ISS score ranges from 1 to 75. Any injury assigned an AIS 6 leads to an ISS 75 .

\section{Excel filtration}

In order to uncover every severely injured trauma patient, we used four sets of exclusion criteria in our filtration process. First, departments considered unlikely to admit severe trauma were excluded (Table 1). Secondly, patients with single injury ICD-10 codes resulting in AIS $\leq 3$ were excluded. Thirdly, patients with multiple injuries in the same body region where the highest injury gave AIS $\leq 3$ and where there were no injuries to other body regions were excluded. Lastly, patients identified as being met by trauma team were excluded using HUH's local trauma register. The filtering was done by using advanced filtering functions in Microsoft Excel 2013 (v15.0). This process excluded a total of 27,865 patients. The remaining patients were manually reviewed.

$2 \times 2$ Contingency table for defining undertriage.

\begin{tabular}{llll}
\hline & $\begin{array}{l}\text { Severely } \\
\text { injured }\end{array}$ & $\begin{array}{l}\text { Not severely } \\
\text { injured }\end{array}$ & Total \\
\hline Trauma team activation & (a) & (b) & $(\mathrm{a}+\mathrm{b})$ \\
No trauma team activation & $(\mathrm{c})$ & $(\mathrm{d})$ & $(\mathrm{c}+\mathrm{d})$ \\
Total & $(\mathrm{a}+\mathrm{c})$ & $(\mathrm{b}+\mathrm{d})$ & $(\mathrm{n})$ \\
\hline
\end{tabular}

$$
\begin{aligned}
& \text { Sensitivity }=a /(a+c) \\
& \text { Undertriage }=1-\text { Sensitivity }=c /(a+c)
\end{aligned}
$$

\section{Traumatic Brain Injury definition}

We defined TBI with reference to the following ICD-10 codes: S06.0-S06.6.

Xiang and colleges defined TB with reference the following ICD-9 codes: 800.0-801.9, 803.0-804.9, 850.0854.0, and 959.01, excluding 995.55. 
Pearson and colleges defined TBI with reference to the following ICD-9 codes: 800.0-801.9, 803.0-804.9, 850.0854,1, 950.1-950.3, 959.01.

Glasgow Outcome Score.

\begin{tabular}{ll}
\hline GOS score & Functional status \\
\hline 5 & $\begin{array}{l}\text { Resumption of normal life, possibly minor neurological } \\
\text { and/or psychological deficits }\end{array}$ \\
4 & $\begin{array}{l}\text { No need for daily support but may require special } \\
\text { adjustments at work. }\end{array}$ \\
3 & $\begin{array}{l}\text { Permanent need for help with daily living } \\
2\end{array}$ \\
1 & $\begin{array}{l}\text { Prolonged state of unresponsiveness for weeks, months } \\
\text { Death }\end{array}$ \\
\hline
\end{tabular}

\section{Abbreviations}

AIS: Abbreviated Injury Scale; GCS: Glasgow Coma Scale; GOS: Glasgow Outcome Score; HUH: Haukeland University Hospital; ICD-10: International Classification of Disease, 10th version; ICD-9: International Classification of Diseases, 9th version; ISS: Injury Severity Score; MOI: Mechanism of Injury; TBI: Traumatic Brain Injury

\section{Availability of data and materials}

The datasets generated and/or analyzed during the current study are not publicly available due to it being part of the local trauma registry but are available from the corresponding author on reasonable request.

\section{Authors' contributions}

TN contributed to the manuscript with design, acquisition and analysis of data, drafting and revision. $\mathrm{PO}$ contributed to the manuscript with acquisition and analysis of data. $A B$ contributed to the manuscript with idea and revision of the manuscript. KU contributed to the manuscript with idea, design, drafting and revision of the manuscript. All authors read and approved the final manuscript.

\section{Ethics approval and consent to participate}

Not applicable.

\section{Consent for publication}

Not applicable.

\section{Competing interests}

The authors declare that they have no competing interests.

\section{Publisher's Note}

Springer Nature remains neutral with regard to jurisdictional claims in published maps and institutional affiliations.

\section{Author details}

${ }^{1}$ Faculty of Medicine, University of Bergen, Haukelandsveien 28, 5009 Bergen, Norway. ${ }^{2}$ Department of Clinical Medicine 1, Jonas Lies vei 65, 5021 Bergen, Norway. ${ }^{3}$ Department of Anaesthesia and Intensive Care, Haukeland University Hospital, Jonas Lies vei 65, 5021 Bergen, Norway. ${ }^{4}$ Regional Trauma Center, Surgical Department, Haukeland University Hospital, Jonas Lies vei 65, 5021 Bergen, Norway.

\section{Received: 3 January 2018 Accepted: 2 July 2018}

\section{Published online: 14 August 2018}

\section{References}

1. Mullins RJ, et al. Outcome of hospitalized injured patients after institution of a trauma system in an urban area. Jama. 1994;271(24):1919-24.

2. Mullins RJ, et al. Influence of a statewide trauma system on location of hospitalization and outcome of injured patients. J Trauma. 1996:40(4):536-45. discussion $545-6$
3. Mullins RJ, et al. Preferential benefit of implementation of a statewide trauma system in one of two adjacent states. J Trauma. 1998;44(4):609-16. discussion 617

4. McDermott FT, Cordner SM. Victoria's trauma care system: national implications for quality improvement. Med J Aust. 2008;189(10):540-2.

5. Gerardo CJ, et al. The rapid impact on mortality rates of a dedicated care team including trauma and emergency physicians at an academic medical center. J Emerg Med. 2011;40(5):586-91.

6. Haas $B$, et al. Survival of the fittest: the hidden cost of undertriage of major trauma. J Am Coll Surg. 2010;211(6):804-11.

7. Haas $B$, et al. The mortality benefit of direct trauma center transport in a regional trauma system: a population-based analysis. J Trauma Acute Care Surg. 2012;72(6):1510-5. discussion 1515-7

8. Kilberg $L$, et al. Effectiveness of implementing a trauma triage system on outcome: a prospective evaluation. J Trauma. 1988;28(10):1493-8.

9. MacKenzie EJ, et al. A national evaluation of the effect of trauma-center care on mortality. N Engl J Med. 2006;354(4):366-78.

10. Champion HR, Sacco WJ, Copes WS. Improvement in outcome from trauma center care. Arch Surg. 1992;127(3):333-8.

11. Pracht $\mathrm{EE}$, et al. Survival advantage associated with treatment of injury at designated trauma centers: a bivariate probit model with instrumental variables. Med Care Res Rev. 2007;64(1):83-97.

12. Meldon SW, et al. Trauma in the very elderly: a community-based study of outcomes at trauma and nontrauma centers. J Trauma. 2002;52(1):79-84.

13. Sampalis JS, et al. Trauma care regionalization: a process-outcome evaluation. J Trauma. 1999;46(4):565-79. discussion 579-81

14. Elliott DC, Rodriguez A. Cost EFFECTIVENESS in trauma care. Surg Clin N Am. 1996;76(1):47-62.

15. Taheri PA, et al. The cost of trauma center readiness. Am J Surg. 2004; 187(1):7-13.

16. Newgard CD, et al. The cost of overtriage: more than one-third of low-risk injured patients were taken to major trauma centers. Health Aff (Millwood). 2013;32(9):1591-9.

17. Newgard CD, et al. Cost-Effectiveness of field trauma triage among injured adults served by emergency medical services. J Am Coll Surg. 2016;222(6): $1125-37$.

18. Trauma, C.o. Resources for Optimal Care of the Injured Patient 2014. 2014; Available from: https://www.facs.org/ /media/files/quality\%20programs/ trauma/vrc\%20resources/resources\%20for\%20optimal\%20care.ashx [cited 20 May 2017]

19. NKT-Traume, N.K.f.T. Nasjonal Traumeplan - Traumesystem i Norge 2016 Nasjonal Kompetansetjeneste for Traumatologi 2015; Available from: http:// traumeplan.no/wp-content/uploads/2017/02/Nasjonal-traumeplan--Traumesystem-i-Norge-2016.pdf [cited 15 May 2017]

20. McCoy CE, Chakravarthy B, Lotfipour S. Guidelines for field triage of injured patients: In conjunction with the Morbidity and Mortality Weekly Report published by the Center for Disease Control and Prevention. West J Emerg Med. 2013;14(1):69-76.

21. Sasser SM, et al. Adoption of the 2006 field triage decision scheme for injured patients. West J Emerg Med. 2011;12(3):275-83.

22. Lerner EB. Studies Evaluating current field triage: 1966-2005. Prehospital Emergency Care. 2006;10(3):303-6.

23. Norcross ED, et al. Application of American College of Surgeons' field triage guidelines by pre-hospital personnel. J Am Coll Surg. 1995;181(6):539-44.

24. Vassar MJ, et al. Fractures in access to and assessment of trauma systems. J Am Coll Surg. 2003;197(5):717-25.

25. Newgard CD, et al. A multisite assessment of the American College of Surgeons Committee on trauma field triage decision scheme for identifying seriously injured children and adults. J Am Coll Surg. 2011;213(6):709-21.

26. Nakamura $Y$, et al. Evaluating age in the field triage of injured persons. Ann Emerg Med. 2012;60(3):335-45.

27. Xiang $\mathrm{H}$, et al. Undertriage of major trauma patients in the US emergency departments. Am J Emerg Med. 2014;32(9):997-1004.

28. Newgard, C.D., et al., Prospective validation of the National Field Triage Guidelines for identifying seriously injured persons. J Am Coll Surg, 2016. 222(2): p. 146-58.e2.

29. Sentralbyrå, S. Folkmengde og befolkningsendringar, 1. januar 2016; Available from: https://www.ssb.no/befolkning/statistikker/folkemengde/aar-per-1-januar/2016-0219?fane=tabell\&sort=nummer\&tabell=256001 [cited 1 Jan 2016]

30. BAKER SP, et al. The injury severity score: a method for describing patients with multiple injuries and EVALUATING emergency care. J Trauma Acute Care Surg. 1974;14(3):187-96. 
31. Medicine, A.f.t.A.o.A. Abbreviated Injury Scale. Available from: https://www. aaam.org/abbreviated-injury-scale-ais/ [cited 7 April 2018].

32. Rehn $\mathrm{M}$, et al. Precision of field triage in patients brought to a trauma Centre after introducing trauma team activation guidelines. Scand J Trauma Resusc Emerg Med. 2009;17(1):1.

33. Dehli $\mathrm{T}$, et al. Evaluation of a university hospital trauma team activation protocol. Scand J Trauma Resusc Emerg Med. 2011;19:18.

34. Dehli $T$, et al. Evaluation of a trauma team activation protocol revision: a prospective cohort study. Scand J Trauma Resusc Emerg Med. 2016;24(1):105.

35. Kann SH, Hougaard K, Christensen EF. Evaluation of pre-hospital trauma triage criteria: a prospective study at a Danish level I trauma Centre. Acta Anaesthesiol Scand. 2007;51(9):1172-7.

36. Mohan, D., et al., Assessing the feasibility of the american college of surgeons\&\#39; benchmarks for the triage of trauma patients. Arch Surg, 2011. 146(7): p. 786-792.

37. Lehmann $\mathrm{R}$, et al. The impact of advanced age on trauma triage decisions and outcomes: a statewide analysis. Am J Surg. 2009;197(5):571-5.

38. Staudenmayer $\mathrm{KL}$, et al. Triage of elderly trauma patients: a populationbased perspective. J Am Coll Surg. 2013;217(4):569-76.

39. Heffernan DS, et al. Normal presenting vital signs are unreliable in geriatric blunt trauma victims. J Trauma. 2010;69(4):813-20.

40. Spaniolas K, et al. Ground level falls are associated with significant mortality in elderly patients. J Trauma. 2010;69(4):821-5.

41. Gerber LM, et al. Impact of falls on early mortality from severe traumatic brain injury. J Trauma Manage\& Outcomes. 2009;3:9-9.

42. Champion HR, et al. Major trauma in geriatric patients. Am J Public Health. 1989;79(9):1278-82.

43. Hranjec T, et al. Mortality factors in geriatric blunt trauma patients: creation of a highly predictive statistical model for mortality using 50,765 consecutive elderly trauma admissions from the National Sample Project. Am Surg. 2012;78(12):1369-75.

44. Demetriades $D$, et al. Old age as a criterion for trauma team activation. J Trauma Acute Care Surg. 2001;51(4):754-7.

45. Demetriades $D$, et al. Effect on outcome of early intensive management of geriatric trauma patients. Br J Surg. 2002;89(10):1319-22.

46. Levin HS, et al. Magnetic resonance imaging and computerized tomography in relation to the neurobehavioral sequelae of mild and moderate head injuries. J Neurosurg. 1987;66(5):706-13.

47. Bergeson $A G$, et al. Clinical rating of cortical atrophy and cognitive correlates following traumatic brain injury. Clin Neuropsychol. 2004;18(4): 509-20.

48. Masel BE, DeWitt DS. Traumatic brain injury: a disease process, not an event. J Neurotrauma. 2010;27(8):1529-40.

49. Corrigan JD, Hammond FM. Traumatic brain injury as a chronic health condition. Arch Phys Med Rehabil. 2013;94(6):1199-201.

50. Stocchetti N, Zanier ER. Chronic impact of traumatic brain injury on outcome and quality of life: a narrative review. Crit Care. 2016;20:148.

51. Henry MC, et al. Evaluation of American college of surgeons trauma triage criteria in a suburban and rural setting. Am J Emerg Med. 14(2):124-9.

52. Franklin GA, et al. Prehospital hypotension as a valid Indicator of trauma team activation. J Trauma Acute Care Surg. 2000;48(6):1034-9.

53. Tinkoff GH, O'Connor RE. Validation of new trauma triage rules for trauma attending response to the emergency department. J Trauma. 2002;52(6): 1153-8. discussion 1158-9

54. Holcomb JB, et al. Manual vital signs reliably predict need for lifesaving interventions in trauma patients. J Trauma Acute Care Surg. 2005;59(4):821-9.

55. Timmons SD, et al. Using the abbreviated injury severity and Glasgow coma scale scores to predict 2-week mortality after traumatic brain injury. J Trauma Acute Care Surg. 2011;71(5):1172-8.

56. Strnad $M$, et al. Predictors of mortality and prehospital monitoring limitations in blunt trauma patients. Biomed Res Int. 2015;2015:983409.

57. Pearson WS, et al. A review of traumatic brain injury trauma center visits meeting physiologic criteria from the American College of Surgeons Committee on trauma/Centers for Disease Control and Prevention field triage guidelines. Prehospital emergency care : official journal of the National Association of EMS Physicians and the National Association of State EMS Directors. 2012;16(3):323-8.

58. Kehoe A, Rennie S, Smith JE. Glasgow coma scale is unreliable for the prediction of severe head injury in elderly trauma patients. Emerg Med J. 2015;32(8):613-5.
59. Cook $\mathrm{CH}$, et al. Reducing overtriage without compromising outcomes in trauma patients. Arch Surg. 2001;136(7):752-6.

60. Wong $\mathrm{TH}$, et al. Combining the new injury severity score with an anatomical polytrauma injury variable predicts mortality better than the new injury severity score and the injury severity score: a retrospective cohort study. Scandinavian journal of trauma, Resuscitation and Emergency Medicine. 2016;24(1):25

61. Paffrath $T$, Lefering $R$, Flohe $S$. How to define severely injured patients? - an injury severity score (ISS) based approach alone is not sufficient. Injury. 2014; 45(Suppl 3):S64-9.

62. Frankema SP, et al. Comparison of current injury scales for survival chance estimation: an evaluation comparing the predictive performance of the ISS, NISS, and AP scores in a Dutch local trauma registration. J Trauma. 2005; 58(3):596-604

63. Salehi $\mathrm{O}$, et al. A new injury severity score for predicting the length of hospital stay in multiple trauma patients. Trauma Monthly. 2016;21(1):e20349.

64. Soni KD, et al. Comparison of ISS, NISS, and RTS score as predictor of mortality in pediatric fall. Burns Trauma. 2017:5:25.

\section{Ready to submit your research? Choose BMC and benefit from:}

- fast, convenient online submission

- thorough peer review by experienced researchers in your field

- rapid publication on acceptance

- support for research data, including large and complex data types

- gold Open Access which fosters wider collaboration and increased citations

- maximum visibility for your research: over $100 \mathrm{M}$ website views per year

At BMC, research is always in progress.

Learn more biomedcentral.com/submissions 